\title{
Pendidikan Kesehatan Kelompok Sebaya (Peer Group) Terhadap Pengetahuan dan Sikap Remaja Putri Tentang Dhysmenorrhea di Pondok Pesantren Sukamiskin Bandung
}

\author{
Yanyan Mulyani, Nurul Khoirunisa \\ Universitas Bhakti Kencana \\ Corresponding author: Yanyan Mulyani (yanyan.mulyani@bku.ac.id) \\ Received: December, 16 2019; Accepted: January, 19 2020; Published: March, 162020
}

\begin{abstract}
ABSTRAK
Salah satu cara agar dapat meningkatkan pengetahuan maupun perilakunya dengan metode Peer Group, yaitu metode pembelajaan dengan berdiskusi mengenai suatu masalah dimana tiap anggotanya adalah teman sebaya.

Desain penelitian menggunakan Quasi-experimental dengan pretest posttest one group without control design. Populasinya adalah remaja putri di Pondok Pesantren Sukamiskin Bandung dan sampel berjumlah 52 responden dengan pengambilan sampel menggunakan teknik Stratified Random Sampling. Pengumpulan data menggunakan kuisioner. Untuk analisa univariat dan bivariate dengan uji Wilcoxon Signed-Rank Test.

Hasil penelitian sebelum dilakukan Peer Group menunjukan 29 responden memiliki pengetahuan kurang dan 28 responden dengan sikap tidak mendukung, setelah dilakukan pendidikan kesehatan yaitu 35 responden memiliki pengetahuan cukup dan 39 responden memiliki sikap mendukung. Uji Wilcoxon Signed-Rank menunjukan p value $<0,05$ berarti terdapat pengaruh Peer Group tentang Dhysmenorrhea terhadap pengetahuan dan sikap..
\end{abstract}

Kata Kunci: Peer Group, Pengetahuan Dhysmenorrhea, Sikap

This is an open-acces article distributed under the terms of the Creative Commons Attribution-ShareAlike 4.0 International License.

\section{PENDAHULUAN}

Masalah kesehatan reproduksi menjadi perhatian bersama karena dampaknya luas menyangkut berbagai aspek kehidupan dan parameter kemampuan negara dalam menyelenggarakan pelayanan kesehatan terhadap masyarakat. Masa remaja (Adolenscence) merupakan masa dimana terjadi transisi masa kanak-kanan menuju dewasa, biasanya antara usia 13 dan 20 tahun, terjadi suatu fase perkembangan yang dinamis dalam kehidupan seorang individu, salah satunya tanda yang khas adalah Pubertas. kematangan seksual remaja putri ditandai dengan adanya menarche (menstruasi pertama kali) merupakan salah satu tanda tejadinya masa reproduksi, tapi banyak diantaranya dalam periode menstruasi ini mengalami masalah, khususnya pada masa remaja sering mengalami nyeri haid (dhysmenorrhea).

Dhysmenorrhea gangguan saat mentruasi yang ditandai dengan adanya nyeri yang berdampak negatif pada aktivitas sehari- hari. Menurut Mariagiulia Bernardi di Indonesia angka kejadiannya 45-93\% prevalensi tertinggi terjadi pada remaja. Berdasarkan penelitian yang telah dilakukan oleh Alaetin Unsal tentang Dhysmenorrhea pada tahun 2015 menyatakan 
prevalensi dhysmenorrhea primer pada perempuan 20\% sampai 90\%. Morbiditas akibat dhysmenorrhea merupakan beban kesehatan remaja yang besar karena selama periode ini beberapa remaja dapat kehilangan nafsu makan dan mereka mungkin tidak masuk sekolah

Selain dengan terapy, penanganan dhysmenorrhea dapat juga dilakukan dengan membiasakan gaya hidup sehat misalnya olahraga ringan, mengkonsumsi makanan yang berserat serta mengurangi kadar gula dan kafein. Dalam suatu penelitian oleh Delia tentang pengaruh pengetahuan remaja putri terhadap sikap pada Dysmenorrhea pada tahun 2016 menyebutkan bahwa apabila pengetahuan tentang dhysmenorrhea kurang, maka akan berpengaruh terhadap perilakunya Apalagi gangguan dhysmenorrhea semakin parah, maka harus berkonsultasi dengan dokter. Terlebih lagi jika suatu individu tidak tahu tentang konsep Dhysmenorrhea itu sendiri seperti tanda gejala khususnya yang berkaitan dengan penanganan, salah satunya seperti mengonsumsi obat-obatan yang tidak sesuai dosis.

Pondok Pesantren Sukamiskin Bandung, jumlah santriwati MTS di Pondok Pesantren Sukamiskin terdapat 112 orang khususnya yang sudah megalami menstruasi ada 102 orang. Dari keseluruhan santri yang sudah mengalami menstruasi ternyata mengalami nyeri haid pada saat menjelang maupun menstruasi berlangsung, dan menunjukan bahwa hanya satu orang saja yang mengetahui pengertian dari dhysmenorrhea atau nyeri haid. Para santri memperoleh sumber informasi eksternal yang mudah dijangkau adalah teman-teman sebaya (peer group), bacaan- bacaan popular, akses internet, dan lain-lain Sumber informasi eksternal ini tidak selalu benar tentang kesehatan reproduksi.

\section{METODE}

Penelitian ini menggunakan metode Quasi Eksperimental dan jenis rancangan secara acak dengan tes awal dan tes akhir (One Group Pretest-Posttest Design). Populasi penelitian ini yaitu seluruh santriwati. Sampel diambil dengan Stratified Random Sampling sampling dengan jumlah sampel 52 responden. Analisis data menggunakan analisis univariat dan bivariate menggunakan uji Wilcoxon Signed- Rank Test dengan bantuan program SPSS 16.

\section{HASIL PENELITIAN}

a. Pengetahuan Remaja Putri tentang Dhysmenorrhea sebelum dan sesudah dilakukan pendidikan kesehatan kelompok sebaya (peer group).

Tabel 4.1.

Distribusi frekuensi Pretest Pengetahuan Remaja Putri tentang Dhysmenorrhea di Pesantren Sukamiskin Bandung

\begin{tabular}{ccc}
\hline Pengetahuan & Frekuensi & Persentase(\%) \\
\hline Baik & 1 & $1,9 \%$ \\
Cukup & 22 & $42,3 \%$ \\
Kurang & 29 & $55,8 \%$ \\
Total & 52 & $100 \%$ \\
\hline
\end{tabular}

Tabel 4.2

Distribusi frekuensi Posttest Pengetahuan Remaja Putri tentang Dhysmenorrhea di Pondok Pesantren Sukamiskin Bandung Tahun 2018

\begin{tabular}{ccc}
\hline Pengetahuan & Frekuensi & Persentase(\%) \\
\hline Baik & 12 & $23.1 \%$ \\
Cukup & 35 & $67.3 \%$ \\
Kurang & 5 & $9.6 \%$ \\
\hline Total & 52 & $100 \%$ \\
\hline
\end{tabular}


b. Sikap Remaja Putri tentang Dhysmenorrhea sebelum dan sesudah dilakukan pendidikan kesehatan kelompok sebaya (peer group)

Tabel 4.3

Distribusi frekuensi Pretest Sikap Remaja Putri tentang Dhysmenorrhea di Pondok Pesantren Sukamiskin Bandung Tahun 2018

\begin{tabular}{ccc}
\hline Sikap & Frekuensi & Persentase(\%) \\
\hline Favourable & 39 & $75.0 \%$ \\
Unfavourable & 13 & $25.0 \%$ \\
\hline Total & 52 & $100.0 \%$ \\
\hline
\end{tabular}

Table 4.4

Distribusi frekuensi Posttest Sikap Remaja Putri tentang Dhysmenorrhea di Pondok

Pesantren Sukamiskin Bandung Tahun 2018

\begin{tabular}{ccc}
\hline Sikap & Frekuensi & Persentase(\%) \\
\hline Favourable & 24 & $46.2 \%$ \\
Unfavourable & 28 & $53.8 \%$ \\
\hline Total & 52 & $100.0 \%$ \\
\hline
\end{tabular}

c. Analisis Bivariat

Tabel 4.7

Uji Hipotesis Pretest dan Posttest Pengetahuan Remaja Putri tentang Dhysmenorrhea di Pondok Pesantren Sukamiskin Bandung Tahun 2018

\begin{tabular}{cccccc}
\hline & $\begin{array}{c}\text { Pengetahuan } \\
\text { Baik }\end{array}$ & Cukup & Kurang & Total (N) & P Value \\
\hline Pretest & 1 & 22 & 29 & 52 & 0.000 \\
Posttest & 12 & 35 & 5 & & \\
\hline
\end{tabular}

Tabel 4.8

Uji Statistik Pretest dan Posttest Sikap Remaja Putri tentang Dhysmenorrhea di Pondok

Pesantren Sukamiskin Bandung Tahun 2018

\begin{tabular}{lcccc}
\hline & & \multicolumn{2}{c}{ Sikap } & Total \\
& Favourable & Unfavourable & P Value \\
& 24 & 28 & 52 & 0.000 \\
Pretest & 39 & 13 & & \\
\hline
\end{tabular}

\section{PEMBAHASAN}

1. Pengetahuan Remaja Putri tentang Dhysmenorrhea Sebelum Dilakukan Pendidikan Kesehatan Sebaya (Peer Group)

Berdasarkan tabel 4.1 sebelum dilakukan pendidikan kesehatan kesehatan kelompok sebaya (peer group), peneltitian terlebih dahulu memberikan pretest dengan memberikan kuisioner kepada responden dan hasilnya sebagian besar responden memiliki pengetahuan yang kurang tentang Dhysmenorrhea yaitu sebanyak 29 responden $(55.8 \%)$ dan hanya 1 responden $(1.9 \%)$ yang memiliki pengetahuan baik.

Dhysmenorrhea adalah nyeri perut yang berasal dari kram rahim dan terjadi selama menstruasi yang mengganggu aktivitas. Rasa nyeri ini dapat disebabkan karena kontraksi otot perut yang terjadi secara terus-menerus saat mengeluarkan darah. Dhysmenorrhea pada umumnya di bagi ke dalam 2 jenis yaitu Dhysmenorrhea primer yang terjadi tanpa adanya 
kelainan ginekologi dan Dhysmenorrhea sekunder yang terjadi akibat adanya kelainan ginekologi.

Dari instrumen penelitian dapat disimpulkan bahwa kebanyakan dari responden memiliki pengetahuan yang kurang tentang Dhysmenorrhea dan rendahnya pemahaman tentang kesehatan reproduksi. Hal ini disebabkan karena kurangnya sumber informasi yang didapatkan oleh responden tentang kesehatan reproduksi khususnya disminor. Begitupun dengan informasi yang mereka dapatkan dari orang tua hanya sebatas garis besarnya saja serta lingkungan yang kurang sumber informasi baik itu diperoleh dari media, buku-buku ataupun pembelajaran yang diberikan oleh guru-guru mengenai kesehatan khususnya kesehatan reproduksi. Selama tinggal di pondok pesantren, para responden hanya mendapatkan informasi mengenai kesehatan reproduksi dari rekan-rekannya sehingga mereka hanya mengacu pada pengalaman tiap individu dan rasa keingintahuan yang kurang akan kesehatan reproduksi walaupun mereka di fasilitasi oleh media elektronik seperti smartphone dan laptop. Terdapat satu responden yang memiliki pengetahuan baik dikarenakan sudah pernah mendapatkan informasi mengenai kesehatan reproduksi diluar pembelajaran di Pondok Pesantren Sukamiskin Bandung.

2. Pengetahuan Remaja Putri tentang Dhysmenorrhea Sesudah Dilakukan Pendidikan Kesehatan Sebaya (Peer Group)

Sesudah dilakukan pendidikan kesehatan dengan metode kelompok sebaya (Peer group) berdasarkan tabel 4.2 didapatkan hasil 35 responden (67.3\%) berpengetahuan cukup dan hanya 5 responden $(9.6 \%)$ berpengetahuan kurang.

Pendidikan kesehatan suatu penerapan konsep pendidikan dalam bidan kesehatan. Dilihat dari segi pendidikan. Kelompok sebaya atau yang biasa disebut peer group adalah kelompok anak-anak atau pemuda yang berumur sama atau berasosiasi seperti persoalanpersoalan anak-anak umur sekolah sampai dengan masa remaja (adolesence). Dalam kelompok sebaya remaja mendiskusikan tentang suatu masalah dan mereka menemukan sesuatu yang tidak mereka temukan sebelumnya. penyampaian pengetahuan melalui peer group yang dilakukan pada remaja bahwa pengetahuan yang disampaikan lebih mudah diterima sehingga mereka dengan sangat mudah untuk menerapkan ilmu-ilmu yang mereka dapat dari teman sebayanya.

Berdasarkan penelitian yang telah dilakukan terdapat peningkatan pengetahuan responden tentang pengetahuan setelah diberikan pendidikan kesehatan tentang Dhysmenorrhea dengan metode pendidikan Peer Group sebanyak 3x dengan durasi masing-masing 30 menit. Dengan metode pendidikan yang telah dilakukan, responden lebih mudah untuk menerima informasi- informasi yang diberikan melalui teman sebayanya. Walalupun terdapat perbedaan pendapat dalam satu kelompok, para responden dapat berdiskusi dan berbagi pengalaman satu sama lain tentang Dhysmenorrhea sehingga mereka sendirilah yang dapat menemukan penyelesaian masalahnya sendiri. Di dalam kegiatan Peer Group para anggotanya menstranfer pengetahuan yang mereka dapatkan baik itu dari orang lain maupun berdasarkan pengalaman, metode tersebut dirasa cukup efektif sehingga responden lebih mudah untuk menyerap informasi yang mereka dapatkan.

3. Sikap Remaja Putri tentang Dhysmenorrhea Sebelum Dilakukan Pendidikan Kesehatan Sebaya (Peer Group)

Berdasarkan tabel 4.2 diketahui bahwa terdapat 24 santri yang memiiki sikap postitif dan 28 santri lainnya memiliki sikap yang negatif tentang Dhysmenorrhea. Sikap merupakan reaksi atau respon seseorang yang masih tertutup terhadap suatu stimulus atau objek. Faktor-faktor yang mempengaruhi sikap diantaranya pengalaman pribadi, pengaruh 
orang lain yang dianggap penting, kebudayaan, media massa dan pengaruh emosi. Sikap seseorang sebagai suatu objek adalah perasaan mendukung atau memihak (favourable) maupun perasaan tidak mendukung atau tidak memihak (unfavourable) pada objek tertentu

Berdasarkan penelitian yang telah dilakukan, sikap yang dimiliki oleh santriwati di Pondok Pesantren Sukamiskin Bandung sebelum diberikan pendidikan kesehatan, diketahui bahwa mereka memiliki sikap yang tidak mendukung terhadap Dhysmenorrhea, tentang pencegahan maupun penanganan untuk mengatatasi Dysmenorrhea mulai dari jarang berolahraga dan mengonsumsi makanan yang pedas. Sebagian besar dari responden berperilaku terhadap Dhysmenorrhea berdasarkan pengalaman dan mengikuti kebiasaan rekan-rekannya selama tinggal di pondok pesantren. Ditambah lagi pengetahuan yang kurang tentang Dhysmenorrhea sehingga para santri tidak mengetahui pencegahan dan penanganan yang baik terhadap Dhysmenorrhea yang di alami. Sementara untuk responden yang memiliki sikap mendukung mereka telah mendapatkan informasi dari luar pondok pesantren baik itu dari anggota keluarganya maupun dari mata pelajaran yang mereka dapatkan pada saat sebelum masuk pondok pesantren.

4. Sikap Remaja Putri tentang Dhysmenorrhea Sesudah Dilakukan Pendidikan Kesehatan Sebaya (Peer Group)

Sesudah dilakukan pendidikan kesehatan dengan metode kelompok sebaya (Peer group) diketahui penilaian sikap didapatkan 39 responden (75\%) memiliki sikap positif dan 13 responden (25\%) dengan sikap negatif. Hal ini menunjukkan bahwa terdapat peningkatan sikap responden sebelum dan sesudah dilakukan pendidikan kesehatan (Peer Group). Kerangka pemikiran yang diwakili oleh para ahli psikologi seperti Louis Thurstone, Rensis Likert dan Charles Osgood. Menurut mereka sikap adalah suatu bentuk evaluasi atau reaksi perasaan. Sikap seseorang sebagai suatu objek adalah perasaan mendukung atau memihak (favourable) maupun perasaan tidak mendukung atau tidak memihak (unfavourable) pada objek tertentu.yang salah satunya dipengaruhi oleh lingkungan dan pengalaman individu. Dalam kelompok sebaya remaja mendiskusikan tentang suatu masalah dan mereka menemukan sesuatu yang tidak mereka temukan di rumah. Bahkan melalui pertemuan kelompok ini dimana setiap anggotanya belajar untuk mengelola suatu masalah dengan interaksi sosial sehingga lebih mudah untuk memberikan motivasi- motivasi dalam suatu hal.

Berdasarkan penelitian yang telah dilakukan, diketahui hasil penilaian sikap setelah diberikan perlakuan yaitu pendidikan kesehatan dengan metode Peer Group terdapat peningkatan dibandingkan dengan hasil sikap sebelum dilakukan pendidikan kesehatan oleh Peer Group. Berdasarkan penelitian yang telah dilakukan sebelumnya, keikutsertaan rekan sebaya akan berpengaruh terhadap pengambilan keputusan seseorang khususnya tentang sikap Dhysmenorrhea dikarenakan mereka bertempat tinggal di pondok pesantren dan kesehariannya lebih menghabiskan waktu bersama sehingga lebih mempunyai kepercayaan dan ketergantungan yang tinggi terhadap satu sama lain. Maka dari itu rekan metode pembelajaran Peer Group dapat memberikan motivasi yang baik tentang Dhysmenorrhea yang tentunya dapat lebih mudah diterima oleh responden.

5. Pengaruh Pendidikan Kesehatan Kelompok Sebaya (Peer Group) Terhadap Pengetahuan dan Sikap Remaja Putri tentang Dhysmenorrhea

Hasil penelitian menunjukan adanya pengaruh pendidikan kesehatan kelompok sebaya (peer group) terhadap pengetahuan dan sikap remaja putri tentang Dhysmenorrhea, yaitu 48 responden untuk pengetahuan dan 30 responden untuk sikap. Dari perhitungan Wilcoxon didapatkan nilai $\mathrm{p}$ value $(0,001)<0,05$ berarti $\mathrm{H} 0$ ditolak dan Ha diterima, 
artinya terdapat pengaruh pendidikan kesehatan kelompok sebaya (Peer group) terhadap pengetahuan dan sikap remaja putri tentang Dhysmenorrhea.

Menurut John W Santrock (2012) kelompok sebaya ialah anak-anak atau remaja yang memiliki usia sama yang saling berinteraksi dengan kawan-kawan sebaya yang berusia sama dan memiliki peran yang unik dalam budaya atau kebiasaan. Dalam kelompok sebaya remaja mendiskusikan tentang suatu masalah dan mereka menemukan sesuatu yang tidak mereka temukan sebelumnya. Pengetahuan adalah hasil dari tahu, dan ini terjadi setelah orang melakukan pengindraan terhadap sesuatu objek tertentu. Sedangkan sikap merupakan reaksi atau respon seseorang yang masih tertutup terhadap suatu stimulus atau objek.

Pengetahuan dan sikap santri tentang Dhysmenorrhea dapat lebih baik dengan dilakukannya pendidikan kesehatan melalui kelompok sebaya (Peer Group) yang dimaksimalkan dengan merekrut satu orang sebagai pemimpin kelompok yang akan memberikan materi atau informasi mengenai masalah yang akan dibahas dan informasi yang disampaikannyapun lebih mudah diterima oleh santri karena berasal dari teman sebaya sehingga mengurangi rasa canggung. Hal ini menunjukan kesesuaian antara teori tentang pendidikan kesehatan kelompok sebaya (Peer Group) bahwa metode ini merupakan metode yang digemari oleh remaja sehingga kemungkinan besar berpegaruh baik pengetahuan maupun sikap seseorang.

\section{SIMPULAN}

Sebagian besar sikap remaja putri tentang Dhysmenorrhea di Pondok Pesantren Sukamiskn tahun 2018 sesudah dilakukan pendidikan kesehatan kelompok sebaya (Peer Group) memiliki sikap positif, serta terjadi peningkatan jumlah responden yang memiliki sikap positif. Terdapat pengaruh pendidikan kesehatan kelompok sebaya (Peer Group) terhadap pengetahuan dan sikap remaja putri tentang Dhysmenorrhea di Pondok Pesantren Sukamiskn tahun 2018.

\section{REFERENSI}

Arikunto. Prosedur Penelitian Suatu Pendekatan Praktek. Jakarta: Rhineka Cipta; 2012.

Arikunto. Prosedur Penelitian Suatu Pendekatan Praktek. Jakarta: Rineka cipta; 2013.

Cunningham G. Obsetri Williams 23 ed. JAKARTA: EGC; 2012.

Delia. Pengaruh Pengetahuan Remaja terhadap Sikap tentang Dismenore. 2016.

Ghina. pendidikan Kesehatan Melalui Peer Group. 8 ed. JAKARTA.2013.

Jakarta: Bina Pustaka; 2014.

Mariagiulia, Bernardi. Kesehatan Reproduksi pada Wanita. 2017

Nadhia. Konsep Pendidikan Remaja Putri Terhdap Kesehatan Reproduksi. 2017.

Notoatmojo S. Metodologi Penelitian Kesehatan Jakarta: Resika Cipta; 2014.

Notoatmojo. Metodologi Penelitian Kesehatan. Jakarta: resika cipta; 2010.

Prawirohardjo $\quad$ S. Ilmu Kebidanan. Jakarta: PT. Bina Pustaka; 2014.

Prawirohardjo, S. Psikolog Remaja. Jakarta. PT RAJAGRAFINO PERSADA; 2012.

Sugiyono. Statistik Untuk Penelitian. Bandung: Alfabeta; 2011.

Susman, S. Adolescent Peer Group Identification . 1 ed . Jakarta.2012.

Susman, S. Adolescent Peer Group Identification and Characterstis. PMC Artickles. 2012.

Titin, S. Peranan Metode Belajar dengan Peer Group. 2013

Unsal, Allaetin. Dhysmenorrhea.2015

Varney, H. Buku Ajar Asuhan Kebidanan. Jakarta: EGC; 2011.

Widikdo. Statistik Kesehatan. Yogyakarta: Mitra Cindekia Press; 2009.

Yuliani, S. Gambaran Pengetahuan Putri tentang Dismenore. 2015. 